\title{
Risk factors for infection with equine influenza virus in donkeys (Equus asinus) in Senegal
}

\author{
Alkaly BADJI $^{1 *}$, Abdoulaye FAYE ${ }^{1}$, Yakhya El Hadji THIOR ${ }^{1}$, Samba SARR $^{1}$, \\ Babacar MBENGUE ${ }^{1}$ and Alphonse SENE $^{2}$
}

${ }^{1}$ Université Alioune Diop de Bambey, Institut Supérieur de Formation Agricole et Rurale, BP 54 Bambey, Sénégal.

${ }^{2}$ Ministère de l'Elevage et des Productions Animales, Inspection Départementale des Services Vétérinaires de Foundiuogne, Sénégal.

*Auteur correspondant ; E-mail: alkaly.badji@uadb.edu.sn ; Tel : +221 775665609

\begin{tabular}{lll}
\hline Received: 27-05-2021 & Accepted: 15-10-2021 & Published: 30-10-2021 \\
\hline
\end{tabular}

\begin{abstract}
In recent years, outbreaks of equine influenza are reported in several countries in the world particulary in Africa. This study is designed to assess the potential risk factors associated with equine influenza virus infection in donkeys in Senegal. The study consists in comparing, depending on the exposure to risk factors, a batch of donkeys infected with the equine influenza virus to another batch of donkeys not infected with the virus during the epizootic of March 2019 which affected the department of Foundiougne. The study reveals that the spread of the equine influenza virus in Foundiougne is associated with the lack of access to veterinary care and infected donkeys were exposed in a ratio of 2 times $(95 \% \mathrm{CI}: 1.38 ; 4.71)$ more than donkeys unharmed. The wandering of donkeys is also linked with the disease. The indicator reflecting the strength of the relationship, the Odds Ratio is 2.06 (95\% CI: $1.10 ; 3.87)$. However, the results indicate that attendance at rural markets (Odds Ratio $=0.90$; 95\% CI: $0.44 ; 1.82$ ), young age (Odds Ratio $=0.90 ; 95 \%$ CI: $0.52,1.55$ ) and female sex (Odds Ratio $=0.97$; $95 \%$ CI: $0.57 ; 1,66)$ do not appear to be related to the spread of the disease. At present, in Senegal, control focused on sensitizing and informing donkey owners on the sanitary management and rational use of donkeys is essential for their well-being.
\end{abstract}

(C) 2021 International Formulae Group. All rights reserved.

Keywords : Influenza virus, donkeys, risk factors, Foundiougne, Sénégal.

\section{INTRODUCTION}

Around the world, donkeys play an important socio-economic role in rural areas. According to the FAO (2020), in sub-Saharan Africa, the donkey population is estimated at 13.7 million heads, living mainly in the countries of the Sahel (Burkina Faso, Chad, Gambia, Niger, Nigeria, Mali, Mauritania and Senegal). Senegal has an estimated donkey population of 471,000 heads (ANSD/MEPA, 2019). They are widely used as a towing force for tractor-drawn crops, transporting people in rural areas, garbage collection and transport of goods in urban areas.

However, they do not receive proper care and suffer heavy losses from various diseases. Indeed, in Africa, from 2018 to 2019, outbreaks of equine influenza are reported in 
several countries with significant deaths in equines. Equine influenza is a highly contagious viral disease that is transmitted by the respiratory route. It is caused by a virus belonging to the family Orthomyxoviridae (Van Maanen and Cullinane, 2002) genus Influenza virus, type A (OIE, 2005) with two subtypes namely H7N7 and H3N8. Previously, H7N7 was considered as the major cause of epidemics whereas latter H3N8 strain is mainly responsible for outbreaks across the globe (Mathew et al., 2010; Bryant et al., 2011; Alves Beuttemmüller et al., 2016). Economically, it is considered one of the diseases with the greatest impact on the equine industry. The disease is officially reported to the OIE by the Mali and Niger during the year 2019 (OIE, 2019a, 2019b, 2019d). Apart these countries, outbreaks of equine influenza are also reported in Cameroon, Chad, Ghana and Sudan (OIE, 2019e).

A study in Nigerian horses showed the presence of $\mathrm{H} 3$ and $\mathrm{H} 7$ subtypes in their area by ELISA (Meseko et al., 2016). The first reports of disease among horses in Senegal were from the regions of Dakar and Thiès in March 2019. By June 2019, eight hundred forty-nine outbreaks were identified in 12 of the 14 regions in Senegal involving 58,300 sick animals. Horses $(\mathrm{n}=146)$ and donkeys $(\mathrm{n}=$ $5,839)$ succumbed to the disease. Analysis by qRT-PCR revealed the presence of the viral genome of an equine influenza $A$ virus, belonging to the H3N8 subtype (Diallo et al. 2020).

The aim of this study was to assess the potential risk factors associated with equine influenza type A virus infection in donkeys in the departement of Foundiougne. The findings will be useful for designing preventive health programs in rural aera in senegal for the optimization of health and welfare of donkeys.

\section{MATERIALS AND METHODS}

\section{Investigation of assumed risk factors}

An epidemiological investigation was carried to compare, depending on the exposure to risk factors, a batch of donkeys infected with the equine influenza type A virus to another batch of donkeys not infected with the virus during the epizootic of March 2019 which affected the department of Foundiougne. The survey was conducted between June and September 2019 in 11 villages (Djilor, Niassène, Diossong, Diagle, Toubacouta, Keur Alassane Gueye, Nioro Alassane Tall, Néma Nding, Keur Samba. Gueye, Keur Sambe Nosso, Diagane Barka) in this department (Figure 1). The agro-breeders, donkey owners, were the target people of the survey. Regular visits were organized during this period to ask them questions in the form of an interview. To this end, a structured questionnaire was used to assess the associated risk factors. Data collected included location and contacts of donkey owners, conduct of donkey breeding, uses of donkeys, disease control strategies, age and sex.

\section{Sampling}

The agro-breeders were chosen randomly from a database established by Union of Farmers Groups of Niombato based in Sokone, a town in the department of Foundiougne. Thus, 85 donkey owners who have their donkeys infected with the virus, and 150 others from the same locality who have their donkeys unharmed were included in the study. For owners who have more than one donkey, only one was retained in the study. Thus, in the batch of infected donkeys $(n=85)$ including males $(n=32)$ and females $(n=53)$, and in the batch of unharmed donkeys $(n=150)$ also including males ( $\mathrm{n}=69)$ and females $(n=81)$. The donkeys retained in the study are of Sahelian breed aged from 1 to 10 years. Their participation required the owners' acceptance to answer questions during our visits. Cases of clinical infections were suspected on the basis of dry harsh cough, fever, tachypnea and/or dyspnea and serous nasal discharge, which later turn mucopurulent observed by local veterinarians.

\section{Statistical analysis}

The $\chi^{2}$ (chi-square) test was used to compare the proportions observed on independent samples according to the formula $\chi^{2}=\sum(\mathrm{ni}-\mathrm{fi}) 2 /$ fi with ni $=$ observation frequency, $\mathrm{fi}=$ theoretical frequency (Toma 
and al., 2010). It was based on the null hypothesis that there was no statistical association between exposure to a suspected risk factor and the onset of equine influenza.

Thus, the lower the value of $p$, the more the observed association is incompatible with the null hypothesis and therefore the more the test is said to be significant. A $5 \%$ probability of rejecting this hypothesis when it is true was chosen.
The strength of the association between the risk factors and disease onset was quantified by calculating the Odds Ratio, an indicator that reflects the strength of this relationship. Thus, the higher the Odds Ratio, the stronger the association between the risk factor and the disease and if the calculated Odds Ratio is equal to 1 , this corresponds to the absence of association between the factor and the disease.
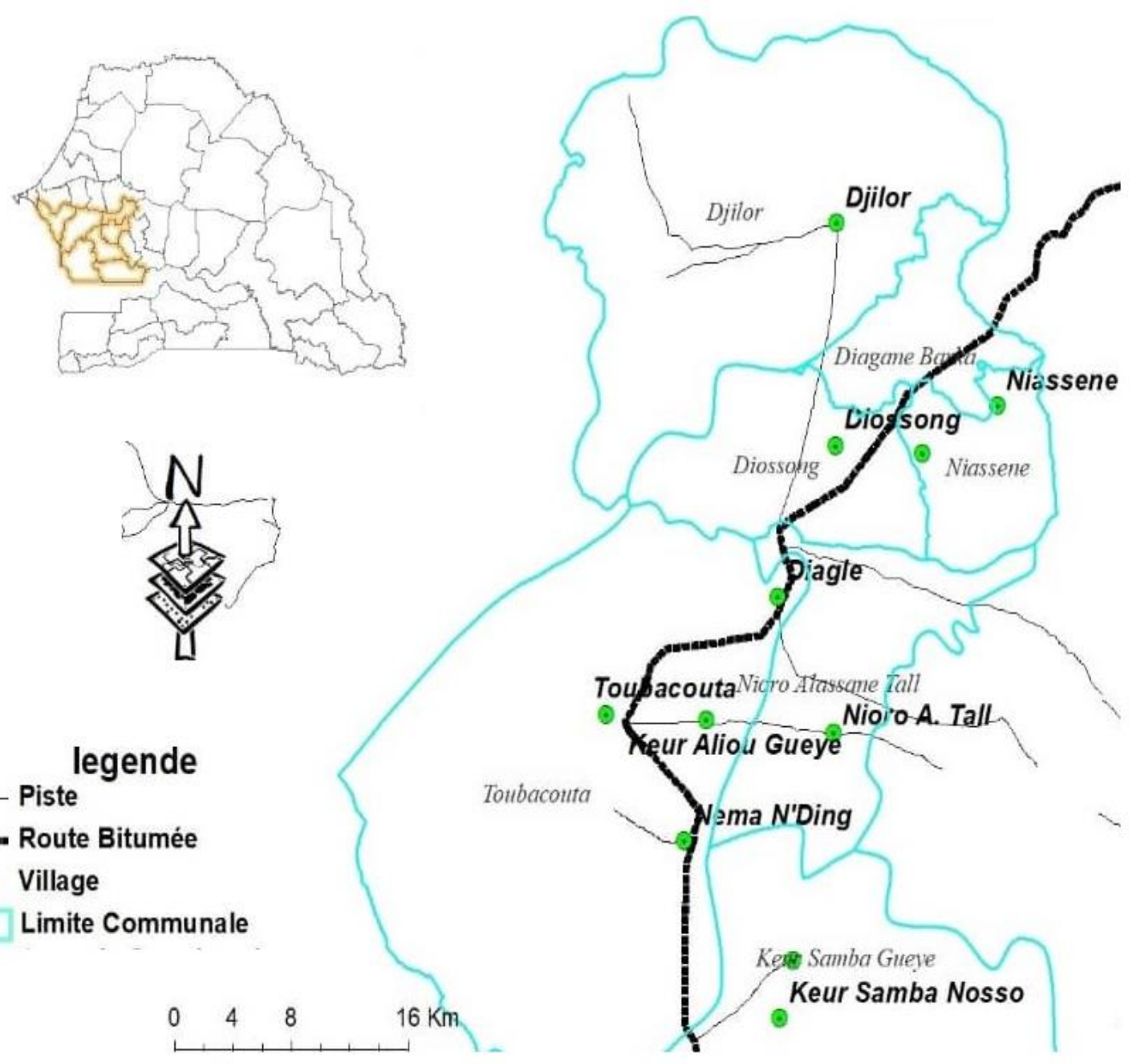

Figure 1 : Map of Senegal showing study area. 


\section{RESULTS}

\section{Attendance of rural markets by donkeys}

The results observed on attendance of rural markets by donkeys are presented in Table 1. The donkeys infected with equine influenza have an exposure percentage of $16.47 \%$, slightly lower than that observed in the donkeys unharmed from influenza equin $(18 \%)$. The difference is not significant $\left(\chi^{2}=\right.$ $0.09 ; \mathrm{P}=0.767)$ and the indicator which reflects the intensity of the relationship, the Odds Ratio is 0.90 (95\% Confidence Interval (CI): $0.44 ; 1.82$ ).

\section{Non access of donkeys to veterinary care}

The results observed on donkeys' lack of access to veterinary care are presented in Table 2. The infected donkeys have an exposure percentage of $78.82 \%$ significantly higher than that observed in donkeys unharmed $(59.33 \%)(\chi 2=9.24 ; P=0.002)$. Infected donkeys were exposed in a ratio of 2 times (95\% CI: $1.38 ; 4.71)$ more than donkeys unharmed.

\section{Wandering donkeys during rest hours}

The results observed on straying donkeys at rest hours are presented in Table 3 .
The infected and unharmed donkeys have exposure percentages of $80 \%$ and $66 \%$, respectively. The percentage of exposure is significantly higher in infected donkeys than in unharmed donkeys $(\chi 2=5.17 ; \mathrm{P}=0.023)$. The indicator reflecting the strength of the relationship, the Odds Ratio is 2.06 (95\% CI: $1.10 ; 3.87)$.

\section{Young age [1 -5 years]}

The results observed on young age are presented in Table 4. Infected and unharmed donkeys have exposure percentages of $38.82 \%$ and $41.33 \%$, respectively. The difference is not significant $(\chi 2=0.14 ; \mathrm{P}=0.706)$ and the calculated Odds Ratio is 0.90 (95\% CI: 0.52, 1.55).

\section{The female sex}

The results observed on gender are presented in Table 5. Infected donkeys have an exposure percentage of $44.70 \%$, slightly lower than that observed in unharmed donkeys $(46 \%)$. The difference is not significant $(\chi 2=$ $0.01 ; \mathrm{P}=0.923)$ and the indicator which reflects the intensity of the relationship, the Odds Ratio is 0.97 (95\% CI: $0.57 ; 1,66$ ).

Table 1: Attendance of rural markets by donkeys.

\begin{tabular}{llll}
\hline & Infected donkeys & Unharmed donkeys & Total \\
\hline Attendance & 14 & 27 & 39 \\
No attendance & 71 & 123 & 196 \\
Total & 85 & 150 & 235 \\
Percentage of exposure & 16,47 & 18 & \\
\hline
\end{tabular}

Table 2 : Non access of donkeys to veterinary care.

\begin{tabular}{llll}
\hline & Infected donkeys & Unharmed donkeys & Total \\
\hline No access to veterinary care & 67 & 89 & 156 \\
Access to veterinary care & 18 & 61 & 79 \\
Total & 85 & 150 & 235 \\
Percentage of exposure & 78.82 & 59.33 & \\
\hline
\end{tabular}


Table 3: Wandering donkeys during rest hours.

\begin{tabular}{llll}
\hline & Infected donkeys & Unharmed donkeys & Total \\
\hline Straying & 68 & 99 & 176 \\
No straying & 17 & 51 & 59 \\
Total & 85 & 150 & 235 \\
Percentage of exposure & 80 & 66 & \\
\hline
\end{tabular}

Table 4: Young age [1 -5 years].

\begin{tabular}{llll}
\hline & Infected donkeys & Unharmed donkeys & Tota \\
& & & $\mathbf{1}$ \\
\hline [1 - 5 years] & 33 & 62 & 100 \\
] $\mathbf{- 1}$ 0 years] & 52 & 88 & 135 \\
Total & 85 & 150 & 235 \\
Percentage of exposure & 38.82 & 41.33 & \\
\hline
\end{tabular}

Table 5 : Sex (female sex).

\begin{tabular}{llll}
\hline & Infected donkeys & Unharmed donkeys & Total \\
\hline Female & 38 & 69 & 34 \\
Male & 47 & 81 & 201 \\
Total & 85 & 150 & 235 \\
Percentage of exposure & 44.70 & 46 & \\
\hline
\end{tabular}

\section{DISCUSSION}

In Senegal, $75 \%$ of the donkey's population is concentrated in the regions of Diourbel, Kaolack, Tambacounda, Kolda and Fatick. The department of Foundiougne, where the study was conducted, has a Sudanese tropical climate with good rainfall which favors the development of the biological vectors of trypanosomiasis and the limitation of horse breeding. Faced with this problem, agro-breeders have chosen the donkey, which is more resistant to this disease and regarded more hardy, which reflects the importance of the donkey population in this department. However, the infectious diseases affecting this group of equids are largely unknown; consequently, the available information regarding infectious diseases affecting working equids is limited in Senegal. This study, carried out for the first time in Senegal, made it possible to assess the link between potential risk factors and infection by the equine influenza virus in the donkey's population.

Rural markets are places where livestock and other agricultural products are traded in Senegal. They would promote the gathering of animals of different species and therefore the transmission of pathogens between them. The difference in the percentage of exposure by attending these markets between the infected donkeys and the unharmed donkeys is not significant. The Odds 
Ratio is close to 1 . These results indicate an absence of association between the frequentation of these markets by donkeys and the onset of the disease. In fact, agro-breeders use the horse-drawn carriage (horse cart) as a means of transport to reach these livestock markets and very few donkeys are present in these places. As a result, low donkey density is generally observed in these markets, hindering direct contact and transmission of the virus.

In contrast, according to Abd El-Rahim, direct contact between horses and donkeys in rural markets encouraged the rapid spread of the disease in Egypt in 2000. Moreover, in terms of wandering, the percentage of exposure was significantly higher in infected than those donkeys unharmed. In addition, donkeys left in stray are twice as exposed as those put in stalls and fed on site. In rural areas in general, particularly in the investigation area, donkeys are mainly used for the traction of agricultural machinery in the fields. They are considered hardy animals and often subjected to intense work. During rest hours, they are left wandering around the concessions where they feed themselves on crop residues in the rangelands and drink together. In the evening, they are parked in outdoor enclosures. This behavior would promote direct contact between them and the transmission of the equine influenza virus. Morley et al. (2000) and Gildea et al. (2011) reported that this contact is strongly associated with virus infection in equines.

According to the results obtained, straying is, a factor in the spread of the disease in this locality. It makes sanitary monitoring of donkeys difficult because of the problem of immobilization. Infected donkeys have a significantly higher percentage of exposure to non-access to veterinary care than that observed in donkeys unharmed. Donkeys who do not benefit from it are twice as likely to develop the disease as those who have access to health care. Access is mainly conditioned by the existence of sufficient health structures and technical staff. However, a very insufficient number of veterinarians and veterinary paraprofessionals are observed in the department of Foundiougne. Professional activity relies on auxiliaries and intermediaries. Agro-breeders are insufficiently sensitized and informed about the health management of the donkey species. Consequently, the local donkey population does not benefit from adequate veterinary health monitoring. Such a situation has probably made these working animals more receptive and more susceptible to the equine influenza virus.

Moreover, the heavy use of donkeys compared to horses is said to have contributed to the weakening of their immune system. This would explain the high mortality recorded in donkeys compared to horses. Regarding young age, infected and unharmed donkeys have comparable exposure percentages and odds ratio less than 1 . These results show an absence of association between young age and infection with the equine influenza virus. They reflect an equal sensitivity between young donkeys (15years) and donkeys over 5 years old. According to Abd El-Rahim et al. (2004), during the 2000 equine influenza epizootic in Egypt, the disease affected equines of all ages and sexes. In contrast, Morley et al. (2000) and Gildea et al. (2011) reported a high susceptibility of young equines to infection with the virus.

This equal sensitivity between the two age layers is explained by the fact that the disease raged for the first time in Senegal and the equines have never been in contact with the equine influenza virus which would have stimulated the production and persistence of antibodies in particularly in old donkeys.

Concerning sex, the percentage of exposure of infected donkeys is slightly lower than that observed in unharmed donkeys with a non-significant difference and an Odds Ratio close to 1 . These results suggest that the susceptibility of donkeys to infection by the virus is not linked to the female sex. Females are just as susceptible to the virus as males. The results obtained are in agreement with those of Laabassi (2012) in Algeria who worked on horses.

\section{Conclusion}

In conclusion, we have studied the link of risk factors and the infection of equine 
influenza virus. The study reveals that the spread of the equine influenza virus in Foundiougne is associated with the lack of access to veterinary care and the wandering of donkeys, especially during the lean season which coincided with the start of the epizootic in Senegal. However, attendance at rural markets, young age (1-5 years) and female sex do not appear to be related to the spread of the disease. These risk factors may combine with other factors to impact the susceptibility of donkeys to the equine influenza virus. To better control this disease, it is essential to strengthen veterinary health structures with equipment and technical personnel in rural areas. Given the possibilities of mutations of the equine influenza virus and the high cost of vaccination, a control focused on sensitizing and informing the donkey owners on the preventive sanitary measures and the rational use of them will contribute to the improvement of the health and welfare of donkeys in Senegal.

\section{AUTHORS' CONTRIBUTIONS}

The research theme was proposed by $\mathrm{AB}$ and $\mathrm{AF}$. YEHT, SS, BM and AS followed and supervised the research work. They were also involved in the editing and formatting of the manuscript.

\section{COMPETING INTERESTS}

The authors have not declared any competing interests.

\section{ACKNOWLEDGEMENTS}

We express our gratitude to the veterinarians operating in the locality for their collaboration.

The authors thanks the donkey owners, the NGO Brook and UGAN for their participation in the realization of this study. We thank Doctor Moussa Thiao for his great contribution to the improvement of the manuscript. We also owe a debt of gratitude the ISFAR administration for their help doing missions to Foundiougne.

\section{REFERENCES}

Alves Beuttemmüller E, Woodward A, Rash A., dos Santos Ferraz LE, Fernandes Alfieri A, Alfieri AA, Elton D. 2016. Characterisation of the epidemic strain of H3N8 equine influenza virus responsible for outbreaks in South America in 2012. Virol J., 13:45. DOI : 10.1186/s12985016-0503-9.

Bryant NA, Rash AS, Woodward AL, Medcalf E, Helwegen M, Wohlfender F, Cruz F, Hermann C, Borchers K, Tiwari A, Chambers TM, Newton JR, Mumford JA, Elton DM. 2011. Isolation and characterisation of equine influenza viruses (H3N8) from Europe and North America from 2008 to 2009. Vet. Microbiol. 147 : 19-27. DOI : 10.1016/j.vetmic.2010.05.040.

Souley MM Diallo AA, Issa Ibrahim A, Alassane A, Issa R, Gagara H, Yaou B, Issiakou A, Diop M, Diouf ROB, LO FT, Lo MM, Bakhoum T, Sylla M, Seck MT, Mesko C, Shittu I, Cullinane A, Settypalli TBK, Lamien CE, Dundon WG. 2020. Transboundary spread of equine influenza viruses (H3N8) in West and Central Africa: Molecular characterization of identified viruses during outbreaks in Niger and Senegal, in 2019. Transboundary and Emerging Diseases, 68(3): 1-10. DOI : org/10.1111/tbed.13779.

El-Rahim A, Hussein M. 2004. An epizootic of equine influenza in Upper Egypt in 2000. Rev. Sci. Tech. Off. Int. Epiz., 23 (3) : 921-930. DOI: 10.20506 / rst.23.3.1539.

FAO.2020. Healthier donkeys to bring stronger livelihoods in Africa. Retrieved from http://www.fao.org/africa/news/detailnews/en/c/1267156/ (Accessed January 2021).

Gildea S, Arkins S, Cullinane A. 2011. Management and environmental factors involved in equine influenza outbreaks in Ireland 2007-2010. Equine Vet. J., 43(5) : 608-617. DOI: $10.1111 / \mathrm{j} .2042-$ 3306.2010.00333.x.

Laabassi F, Mamache B, Gaudaire D, Amelot G, Nasri AM, Pronost S, Legrand L, Hans 
A 2012. Study of equine influenza infection in horses in Algeria, doctoral thesis es-sciences. Journal Med. Vet., 163(5) : 227-234.

Mathew T, Dhama K, Pawaiya RVS., Mahendran M. 2010. Equine influenza, in Advances in Medical and Veterinary Virology, Immunology, and Epidemiology-Vol. 7: Tropical Viral Diseases of Large Domestic Animals-Part 1, ed Mathew T. (West Orange, NJ; United Kingdom: Thajema Publishers; Xlibris Corporation), Chapter 133-151.

Meseko CA., Ehizibolo DO, Nwokike EC, Wungak YS. 2016. Serological evidence of equine influenza virus in horse stables in Kaduna, Nigeria. J. Equine Sci., 27 : 99-105. DOI : org/10.1294/jes.27.99.

Morley PS, Townsend HG, Bogdan JR and Haine S. 2000. Risk factors for disease associated with influenza virus infec tions during three epidemics in horses. Journal Am. Vet. Med. Ass., 216(4) : 545-550. DOI.org/10.2460/javma.2000.216.545.

OIE. 2005. Terrestrial Manual. Equine influenza : Chapter 2.5.5. www.oie.int., pp. 759-771.

National Agency for Statistics and Demography Senegalese (ANSD) /Ministry of Economy, Finance and Planning (MEPA). 2019. Economic and social situation of Senegal, Livestock, pp 216-222.

OIE. 2019b. WAHI country report Niger. Retrieved from https://www. Oie.int/wahis_2/public/wahid.php/Revie wreport/Review ?page_refer=MapFullEv
entReport \& reportid=31079. (Accessed january 2021).

OIE. 2019a. WAHI country report Mali. Retrieved from https ://www. Oie.int/wahis_2/public/wahid.php/Revie wreport/Review ?page_refer=MapFullEv entReport \& reportid=31526. (Accessed january 2021).

OIE. 2019c. WAHIS country report Senegal. Retrieved from https:// www.oie.int/wahis_2/public/wahid.php/ Reviewreport/Review?page_refer=MapF ullEventReport \& reportid $=30070$. (Accessed january 2021).

OIE. 2019d. WAHIS country report Sudan. Retrieved from https://www.oie.int/wahis_2/public/wahi d.php/Reviewreport/Review?page_refer $=$ MapFullEventReport \& reportid = 30986. (Accessed january 2021).

OIE. 2019e. Expert surveillance panel on equine influenza vaccine composition, oie headquarters, 4 April 2019.

Retrieved from https://www.oie.int/en/ourscientific-expertise/specific-informationandrecommendations/equineinfluenza/(Accessed january 2021).

Toma B, Difour B, Benett JJ, Sanaa M. Shaw A, Moutou F. 2010. Epidemiology applied to the collective fight against transmissible animal diseases. AEEMA, $600 \mathrm{p}$.

Van Maanen C and Cullinane A. 2002. Equine influenza virus infections: An update, Veterinary Quarterly, 24(2) : 79-94. DOI: 10.1080/01652176.2002.9695127. 